\title{
Artikel
}

\section{Renteverplichtingen tijdens de wettelijke vereffening}

Mr. S.R. Baetens*

\section{Inleiding}

Op 17 september 2021 verscheen de uitspraak van de Hoge $\operatorname{Raad}^{1}$ waarin antwoord werd gegeven op enige prejudiciële vragen over hoe om te gaan met rente tijdens de wettelijke vereffening van een nalatenschap. In dit artikel werp ik een blik op deze beantwoording en kom ik tot de conclusie dat de uitspraak (nog) niet de duidelijkheid verschaft waar de rechtspraktijk behoefte aan heeft.

\section{De aanleiding tot de prejudiciële vragen}

Aan de beantwoording van de prejudiciële vragen door de Hoge Raad lag een verzoek van de kantonrechter van rechtbank Noord-Holland ${ }^{2}$ ten grondslag. In die kwestie speelde het volgende. De vader beschikte bij uiterste wilsbeschikking over zijn nalatenschap en bepaalde dat zijn zes eigen kinderen en zijn echtgenote tot erfgenamen werden benoemd. Twee van de zes kinderen kreeg hij samen met zijn echtgenote. Alle kinderen verkregen een vordering op de langstlevende, die eerst opeisbaar zou worden bij haar overlijden. ${ }^{3}$ Relevant was dat de va-

Mr. S.R. Baetens is advocaat bij SCG Advocaten te Eindhoven

HR 17 september 2021, ECLI:NL:HR:2021:1272.

Rb. Noord-Holland 11 januari 2021, ECLI:NL:RBNHO:2021:205 en Rb. Noord-Holland 8 februari 2021, ECLI:NL:RBNHO:2021:1240.

3 Of de vader een ouderlijke boedelverdeling onder oud erfrecht in zijn testament opnam of de wettelijke verdeling van titel 4.3.1 BW van toepas- der bij uiterste wil bepaalde dat de niet-opeisbare vorderingen van zijn kinderen vermeerderd zouden worden met rente vanaf het moment dat zijn nalatenschap open zou vallen tot het moment van betaling van de vordering. ${ }^{4}$

De moeder overleed enkele jaren later. Zij benoemde slechts haar eigen (twee) kinderen tot erfgenamen. Deze kinderen aanvaardden de nalatenschap van hun moeder beneficiair, waarna door de rechtbank een vereffenaar werd benoemd. Een drietal jaar na het overlijden van de moeder deponeerde de vereffenaar zijn uitdelingslijst ter griffie. Hij vermeldde daarop wel de vorderingsrechten van de kinderen van de vader, maar verhoogde deze niet met rente over de periode na het overlijden van de moeder, een en ander onder verwijzing naar het zijns inziens via artikel 4:218 lid 5 van het Burgerlijk Wetboek (BW) van overeenkomstige toepassing zijnde faillissementsrechtelijke fixatiebeginsel van artikel 128 van de Faillissementswet (Fw).

De kinderen van de vader gingen in verzet en stelden dat hun vorderingen wel aan een rentebijtelling na overlijden van de moeder onderhevig zijn. Het faillissementsrechtelijke fixatiebeginsel is, zo meenden de kinderen, niet tijdens de vereffening van toepassing, waarbij zij verwezen naar een uitspraak van de rechtbank Noord-Nederland van 9 augustus 2017. ${ }^{5}$ Omdat de rentebijtelling volgens het testament van de vader pas eindigt per de datum van voldoening van de vorderingen, menen zij recht te hebben op rente tot dat moment.

sing verklaarde, wordt uit de uitspraak niet duidelijk. De gevolgen voor de verdere beantwoording zijn in beide situaties hetzelfde.

4 Zie Parket bij HR 4 juni 2021, ECLI:NL:PHR:2021:556, r.o. 1.2.

5 Rb. Noord-Nederland 9 augustus 2017, ECLI:NL:RBNNE:2017:3158. 
De kantonrechter ${ }^{6}$ overwoog dat feitelijk de vraag of het faillissementsrechtelijke fixatiebeginsel van artikel 128 FW via de weg van artikel 4:218 lid 5 BW van overeenkomstige toepassing is ter beantwoording voorligt. Dit beginsel houdt dus in dat per de aanvangsdatum van de vereffening de vorderingen worden 'gefixeerd'; deze worden daarmee onveranderlijk en worden dan dus niet zelfstandig verhoogd met (bijvoorbeeld) rente.

De kantonrechter vatte in diens tussenbeschikking van 11 januari 2021 de stand van zaken in de jurisprudentie en literatuur over dit vraagstuk samen. De rechtspraak vertoonde een verdeeld beeld. Waar de rechtbank Noord-Nederland in voornoemde uitspraak overwoog dat er geen aanleiding is om artikel $128 \mathrm{Fw}$ van overeenkomstige toepassing te verklaren tijdens de wettelijke vereffening, overwoog het gerechtshof Amsterdam precies het tegenovergestelde: ${ }^{7}$

'Bepalingen van de Faillissementswet (FW) zijn voor zoveel mogelijk van toepassing. Het hof zal hierbij aansluiten [sic] zoeken, nu voor de vereffening een specifieke regeling ontbreekt. Op grond van artikel 128 FW kunnen schuldeisers in een faillissement in beginsel opkomen voor het bedrag dat zij op dat moment van de faillietverklaring te vorderen hebben. Analoge toepassing van deze bepaling leidt ertoe dat vanwege de toepassing van de wettelijke vereffening en het feit dat de omvang van de nalatenschap negatief is, geen wettelijke rente in rekening kan worden gebracht/verschuldigd is. Het hof ziet daarom net als de rechtbank aanleiding de wettelijke rente buiten beschouwing te laten.'

Ook in de literatuur verschenen afwijkende visies. Naar aanleiding van voornoemde uitspraken schreef $\mathrm{ik}^{8}$ een artikel, waarin ik betoogde dat uit de parlementaire geschiedenis niet te herleiden is dat de wetgever heeft beoogd het faillissementsrechtelijke fixatiebeginsel van artikel $128 \mathrm{Fw}$ - dat ziet op rentes - via artikel 4:218 lid $5 \mathrm{BW}$ van overeenkomstige toepassing te laten zijn tijdens de wettelijke vereffening. Ik beschreef dat de verwijzing van artikel 4:218 lid 5 BW specifiek ziet op de wijze waarop bepaalde vorderingen dienen te worden opgenomen op de uitdelingslijst, zoals vorderingen onder een opschortende of ontbindende voorwaarde, waarvan het tijdstip van opeisbaarheid onbepaald is of waarvan de waarde onbepaald of onzeker is. Fixatie is dan essentieel. Bij verschenen rente is dat mijns inziens anders, omdat het in het algemeen eenvoudig is om vast te stellen welk bedrag verschuldigd is.

Van Anken ${ }^{9}$ meent dat het fixatiebeginsel ook ter zake van rentes van toepassing is tijdens de wettelijke veref- fening. Uit de parlementaire geschiedenis ${ }^{10}$ volgt dat volgens de wetgever onder andere de artikelen 130 en $133 \mathrm{Fw}$ in de wettelijke vereffening dienen te worden toegepast. Aan die artikelen ligt het fixatiebeginsel ten grondslag. Bovendien staan deze artikelen in dezelfde afdeling van de Faillissementswet als artikel 128 Fw. Deze afdeling kent als opschrift: 'Van de verificatie der schuldvorderingen'. Volgens Van Anken is er daarom geen goede reden te bedenken om de artikelen 130 en $133 \mathrm{Fw}$ wel, maar artikel $128 \mathrm{Fw}$ niet toe te passen in de erfrechtelijke vereffening. ${ }^{11}$

Ook Biemans ${ }^{12}$ concludeerde dat het goed verdedigbaar is dat het faillissementsrechtelijke fixatiebeginsel ook met betrekking tot rentes op de wettelijke vereffening van toepassing is. Verbintenissen die ná het begin van de vereffening ontstaan uit wederkerige overeenkomsten en andere rechtsverhoudingen waarbij de erflater partij was (zoals renteverplichtingen), moeten zijns inziens worden beoordeeld overeenkomstig de leer uit Credit Suisse/Jongepier q.q. ${ }^{13}$ Uit artikel 24 Fw volgt dat de boedel niet aansprakelijk is voor verbintenissen van de schuldenaar die na faillietverklaring ontstaan, tenzij de boedel ten gevolge daarvan is gebaat. Pas je dit uitgangspunt op de vereffening toe, dan vormen renteverplichtingen na overlijden als zodanig geen schuld als bedoeld in artikel 4:7 lid 1 onder a BW.

Vorderingen die voortvloeien uit een reeds bestaande rechtsverhouding van de erflater kunnen evenwel volgens Biemans ter verificatie worden ingediend, ook als ze pas ná het begin van de vereffening zijn ontstaan. De verificatie van dergelijke nieuwe (rente)vorderingen is echter uitsluitend mogelijk indien en voor zover zij reeds besloten lagen in de rechtspositie van de schuldeiser zoals die bij het intreden van de vereffening bestond. Dat laatste is volgens Biemans enkel het geval indien de nieuwe vorderingen geen uitbreiding opleveren van de aanspraken die deze schuldeiser op grond van die rechtspositie op dat tijdstip al had. Het fixatiebeginsel houdt immers in dat de rechtspositie van een schuldeiser na het begin van de vereffening niet te zijnen gunste mag worden gewijzigd. Kort en goed komen de rentevorderingen pas aan voldoening toe, als er nog een overschot resteert na de voldoening van de schulden als bedoeld in artikel 4:7 BW.

De tegenstrijdige rechtspraak en visies in de literatuur gaven de kantonrechter aanleiding tot het stellen van de navolgende prejudiciële vragen aan de Hoge Raad:

'- Moet artikel 4:218 lid 5 BW aldus worden uitgelegd dat het in artikel 128 van de Faillissementswet neergelegde fixatiebeginsel van overeenHof Amsterdam 28 maart 2017, ECLI:NL:GHAMS:2017:1031, r.o. 3.26. S.R. Baetens, De verschuldigdheid van rente bij de vereffening van nalatenschappen, Tijdschrift Relatierecht en Praktijk 2018/79.

9 J.M. van Anken, Postume rente in de wettelijke vereffening, Tijdschrift Erfrecht 2018, afl. 3, p. 53-56.
10 MvA II, Parl. Gesch. Boek 4 BW, p. 2014.

11 Zie ook J.M. van Anken, Fixatie in faillissement en vereffening, WPNR 2018, afl. 7213, p. 820-828.

12 J.W.A. Biemans, Overeenkomst, overlijden en vereffening van nalatenschappen, Tijdschrift voor Insolventierecht 2020/41.

13 HR 23 maart 2018, ECLI:NL:HR:2018:424. 
komstige toepassing is op de vereffening van een nalatenschap?

- Indien de vorige vraag bevestigend wordt beantwoord: dient daarbij onderscheid gemaakt te worden tussen de zogenaamde "zware" en de "lichte" vereffening? Met andere woorden, is het fixatiebeginsel ook van toepassing op erfgenaam-vereffenaars op wie de verplichtingen omschreven in artikel 4:218 BW niet rusten? Zo ja, met ingang van welke datum moeten de rentevorderingen in dat geval worden gefixeerd?

- Indien de vraag ontkennend wordt beantwoord: dienen de rentevorderingen zowel bij een positief als bij een negatief saldo van de nalatenschap op de uitdelingslijst te worden opgenomen? Indien deze alleen bij voldoende baten op de uitdelingslijst moeten worden geplaatst, zijn er algemene richtlijnen te geven wanneer sprake is van voldoende baten (rekening houdend met bijvoorbeeld oplopende rente en vereffeningskosten)?'

\section{De conclusie van de procureur-generaal van de
Hoge Raad}

De procureur-generaal van de Hoge Raad concludeerde op 4 juni $2021^{14}$ en beantwoordde de prejudiciële vragen als volgt.

Artikel 4:218 lid 5 BW verklaart de voorschriften van de Faillissementswet 'zoveel mogelijk' van overeenkomstige toepassing voor een drietal zaken, te weten bij de berekening van ieders vordering, het opmaken van de uitdelingslijst en het verzet daartegen. Zoals de Hoge Raad in zijn beschikking van 21 december $2018^{15}$ wat betreft het verzet tegen de uitdelingslijst heeft vooropgesteld, wijzen de bewoordingen 'zoveel mogelijk' in artikel 4:218 lid 5 BW erop dat overeenkomstige toepassing van de voorschriften van de Faillissementswet op de verzetsprocedure uitgangspunt en geen uitzondering is. Daarmee valt volgens de procureur-generaal niet in te zien waarom deze overweging niet ook zou impliceren dat overeenkomstige toepassing van de voorschriften van de Faillissementswet bij de in artikel 4:218 lid 5 BW genoemde berekening van ieders vordering en het opmaken van de uitdelingslijst eveneens uitgangspunt en geen uitzondering is.

Door de bevestigende beantwoording van de eerste vraag beantwoordt de procureur-generaal ook de tweede vraag. Zij maakt onderscheid in vier situaties.

In de situatie dat de verplichtingen van artikel 4:218 BW ingevolge artikel 4:221 lid 1 BW niet op de beneficiair aanvaard hebbende erfgenamen rusten, geldt het fixatiebeginsel niet, omdat er geen sprake is van een insol-

14 Parket bij HR 4 juni 2021, ECLI:NL:PHR:2021:556.

15 HR 21 december 2018, ECLI:NL:HR:2018:2393, NJ 2019/39. vente nalatenschap. Mijns inziens bedoelt de procureur-generaal hiermee dat in het geval de boedel ruimschoots toereikend is om alle schulden, waaronder verschenen rentes, te voldoen, er geen aanleiding is om te fixeren. Iedere schuldeiser kan dan immers ten volle worden voldaan. ${ }^{16}$ Of de procureur-generaal hiermee ook meende dat in een insolvente boedel, waarin de verplichtingen van artikel 4:218 BW niet zijn opgelegd, het fixatiebeginsel dient te gelden, blijft daarmee onduidelijk.

Indien de kantonrechter de verplichtingen van artikel 4:218 BW wel van toepassing heeft verklaard, ligt fixatie wel voor de hand en wel per de datum van de beschikking van de kantonrechter, waarin de kantonrechter heeft bepaald dat de verplichtingen van artikel 4:218 BW op de erfgenamen/vereffenaars rusten.

Indien een vereffenaar door de rechtbank is benoemd en op hem de verplichting rust om een uitdelingslijst te deponeren, dan heeft het fixatiebeginsel te gelden, aldus de procureur-generaal. Als er sprake is van een situatie als bedoeld in artikel 4:221 lid 2 BW, zou het fixatiebeginsel dan weer niet hoeven te gelden. Dat artikel bepaalt dat een door de rechter benoemde vereffenaar geen rekening en verantwoording behoeft af te leggen en geen uitdelingslijst behoeft neer te leggen als alle schulden ten volle worden voldaan tijdens de vereffening, of wanneer de kantonrechter hem van deze neerlegging vrijstelt.

Samenvattend kan worden gesteld dat de procureur-generaal meent dat, ongeacht de vraag of de nalatenschap moet worden vereffend door de erfgenamen of door een door de rechter benoemde vereffenaar, de rente dient te worden voldaan tot aan het moment van betaling van de hoofdsom en verschuldigde rente indien de boedel daartoe voldoende toereikend is. Is er een tekort, dan is er volgens de procureur-generaal (in beginsel) reden om te fixeren per de aanvangsdatum van de vereffening. Dat betekent dat éérst de schulden als bedoeld in artikel 4:7 lid 1 BW per de sterfdatum ${ }^{17}$ dienen te worden voldaan, voordat aan de (eventuele) betaling van verschuldigde rentes kan worden toegekomen. ${ }^{18}$
16 Opgemerkt wordt dat de kantonrechter de verplichtingen van art. 4:218 $\mathrm{BW}$ via art. 4:221 lid $1 \mathrm{BW}$ ook van toepassing kan verklaren in positieve boedels.

17 Bepaalde kosten als boedelkosten/vereffeningskosten uitgezonderd. Aannemelijk is dat de rentevorderingen van separatisten buiten de fixatie vallen, zie art. 4:223 lid 1 BW jo. art. 57-60 Fw.

18 Vgl. Biemans, Overeenkomst, overlijden en vereffening van nalatenschappen, voor een soortgelijke benadering. 


\section{De beantwoording van de prejudiciële vragen door de Hoge Raad}

De op 17 september 2021 verschenen uitspraak van de Hoge Raad heeft menig in de erfrechtpraktijk werkzame professional verrast. De Hoge Raad beantwoordde de prejudiciële vragen contrair aan de conclusie van de procureur-generaal.

De Hoge Raad overweegt dat uit de tekst van artikel 4:218 lid 5 BW zelf en uit de wetsgeschiedenis ${ }^{19}$ geen directe aanwijzing valt te herleiden dat de wetgever mede heeft beoogd artikel $128 \mathrm{Fw}$ van overeenkomstige toepassing te laten zijn. Daarentegen wijst de Hoge Raad op aanwijzingen waaruit zou volgen dat de wetgever het fixatiebeginsel van artikel $128 \mathrm{Fw}$ niet zonder meer passend acht voor de vereffening van een nalatenschap. Zo wordt verwezen naar de vervallen verklaarde regeling voor beneficiaire aanvaarding (art. 4:1070 e.v. (oud) BW). In die oude bepalingen werd verwezen naar artikel 490 (oud) Rv, waaruit volgde dat er rekening met rente moest worden gehouden tot het sluiten van een proces-verbaal van verdeling. Volgens de Hoge Raad heeft de wetgever ${ }^{20}$ onder ogen gezien dat artikel $490 \mathrm{Rv}$ zou gelden bij iedere rangregeling buiten faillissement en daarmee ook bij de vereffening van een nalatenschap. Het niet opnemen van een overeenkomstige bepaling in het nieuwe BW is dan ook geen omissie, maar wijst erop dat de wetgever het fixatiebeginsel niet van overeenkomstige toepassing wilde laten zijn.

Vervolgens vergelijkt de Hoge Raad de karakters van een faillissement en een vereffening. Waar er bij een faillissement bij hoge uitzondering sprake is van een positieve boedel, is dat bij een vereffening veel vaker het geval. Fixatie is dan overbodig, aldus de Hoge Raad, en leidt zelfs tot onwenselijke situaties. In een faillissement kan, bij een resterend positief saldo, de schuldeiser alsnog via artikel 2:23 BW of via een tweede faillissement aanspraak maken op de rentebetaling. De Hoge Raad acht het met het oog op de kosten van een schuldeiser onwenselijk dat een tweede vereffening zou moeten worden gevraagd, gesteld dat een tweede vereffening al mogelijk is.

Als rentes buiten beschouwing blijven en er vindt een uitkering van het overschot aan de beneficiair aanvaard hebbende erfgenaam plaats, kan deze rente alsnog op grond van artikel 4:184 lid 3 BW op het eigen vermogen van de beneficiair aanvaard hebbende erfgenaam worden verhaald (tot het bedrag van diens verkrijging). Dat staat volgens de Hoge Raad haaks op de bedoeling van de wet om de beneficiair aanvaard hebbende erfgenaam te vrijwaren van verhaal op zijn overige vermogen.
Rechtsoverweging 2.17 verdient speciale aandacht, mede vanwege de gevolgen die deze met zich brengt. Ik citeer:

'Legaten worden slechts ten laste van de nalatenschap voldaan indien alle andere schulden van de nalatenschap daaruit ten volle kunnen worden voldaan (art. 4:120 lid 1 BW). De vereffenaar heeft tot taak de schulden van de nalatenschap te voldoen en, voor zover voor dat doel noodzakelijk, legaten te verminderen (art. 4:211 BW). Het ligt in de rede dat deze taak om legaten op de voet van art. 4:120 lid 2 BW te verminderen met het oog op de voorrang die bij de voldoening aan de andere schulden van de nalatenschap toekomt, ook geldt als het gaat om schulden uit rente. Zonder vermindering zou de legataris bovendien blootstaan aan verhaal voor de rente op de voet van art. 4:220 lid 3 BW. De tijdens de vereffening over een schuld van de erflater verschuldigd geworden rente is immers eveneens aan te merken als een schuld als bedoeld in art. 4:7 lid 1, onder a, BW.'

Deze overweging kan mijns inziens niet worden gezien als een reden waarom toepassing van het fixatiebeginsel onwenselijk is, maar slechts als de beschrijving van de wijze waarop het buiten toepassing laten van het fixatiebeginsel dan uitwerkt voor, in dit geval, legaten. Deze overweging is met name van belang vanwege de onduidelijkheden die de beantwoording van de derde prejudiciële vraag opwerpt.

De Hoge Raad overweegt dus dat het fixatiebeginsel van artikel $128 \mathrm{Fw}$ niet van overeenkomstige toepassing is op de wettelijke vereffening via artikel 4:218 lid 5 BW. De derde prejudiciële vraag is dan uiteraard interessant: hoe werkt dit vervolgens uit? De Hoge Raad antwoordde daarop in rechtsoverweging 2.21:

'Op de uitdelingslijst behoeven vorderingen ter zake van na het openvallen van de nalatenschap lopende rente, evenals geldt voor andere vorderingen, slechts batig gerangschikt te worden opgenomen voor zover zij kunnen worden voldaan uit het na de vereffening resterende, uit de rekening en verantwoording blijkende, saldo van de nalatenschap. Deze rentevorderingen komen in aanmerking voor opneming op de uitdelingslijst, maar pas na de als boedelkosten aan te merken vereffeningskosten. Tot deze vereffeningskosten behoort het loon dat op de voet van art. 4:206 lid 3 BW vóór het opmaken van de uitdelingslijst door de kantonrechter wordt vastgesteld.'

\section{Conclusies en onduidelijkheden}

Het antwoord van de Hoge Raad op de prejudiciële vraag of het faillissementsrechtelijke fixatiebeginsel van artikel 128 Fw via de weg van artikel 4:218 lid 5 BW van toe- 
passing is op de wettelijke vereffening, is helder; dat luidt ontkennend.

De overwegingen van de Hoge Raad lijken voor wat betreft de vraag of rente na aanvang van de vereffeningsverplichting nog verschuldigd kan zijn, aan te sluiten bij de algemene opinie in de literatuur. Rente is (mits van toepassing) verschuldigd. De vraag hoe een rentevordering door een vereffenaar dan moet worden behandeld en de vraag welke rang een rentevordering toekomt, zijn van groter belang.

Een grammaticale duiding van de eerste twee zinnen van rechtsoverweging 2.21 van de uitspraak van de Hoge Raad leidt tot een tegenstrijdig beeld. De eerste zin behelst de woorden 'batig gerangschikt'. Deze woorden komen in Boek 4 BW slechts in artikel 4:219 terug en zien op de situatie dat een nalatenschap op verzoek van een schuldeiser van een verwerpende erfgenaam wordt vereffend. Diens vordering wordt dan slechts 'batig gerangschikt' op de uitdelingslijst, hetgeen betekent dat hij zich slechts kan verhalen op het overschot dat aan de verwerpende schuldenaar zou zijn toegekomen, als hij niet had verworpen. Als een vergelijkbare toepassing voor rente zou gelden, zou dat dus betekenen dat éérst alle schulden van artikel 4:7 lid 1 BW dienen te worden voldaan en daarna pas de rentes. Dat houdt de facto een fixatie per de aanvangsdatum van de vereffening in.

Ook het tweede deel van die zin lijkt in die richting te wijzen. De rentes behoeven slechts op een uitdelingslijst te worden opgenomen, voor zover zij kunnen worden voldaan uit het na de vereffening resterende, uit de rekening en verantwoording blijkende saldo van de nalatenschap. De vereffening behelst op grond van artikel 4:211 jo. artikel 4:215 BW de voldoening van alle schulden van de nalatenschap (zie art. 4:7 BW). Door de rentes hier afzonderlijk te benoemen lijkt het alsof de Hoge Raad de renteverplichting als een separate, nakomende verplichting ziet. Ook de verwijzing naar het saldo van de nalatenschap impliceert dat de rente zou moeten worden voldaan ná voldoening van alle schulden van artikel 4:7 lid 1 BW. Waar in de wet naar het saldo van de nalatenschap wordt verwezen, ziet dat telkens op het verschil tussen de (waardes van de) activa en de passiva van artikel 4:7 lid 1 BW. Zo ziet artikel 4:202 lid 2 BW op de situatie dat een wettelijke vertegenwoordiger de kantonrechter kan verzoeken niet te hoeven vereffenen als 'het saldo van de nalatenschap positief is', oftewel wanneer alle schulden uit de bezittingen kunnen worden voldaan. Artikel 4:220 lid 2 BW wijst naar de situatie als een schuldeiser pas opkomt na het verbindend worden van de uitdelingslijst; deze kan zich dan slechts verhalen op de onverkochte goederen en 'het saldo van de nalatenschap'. Perrick ${ }^{21}$ beschouwt dat als 'het overschot'.

Deze duiding staat evenwel haaks op rechtsoverweging 2.17, waarin de Hoge Raad overweegt dat rentes zijn aan

te merken als een schuld als bedoeld in artikel 4:7 lid 1 onder a BW. De Hoge Raad prevaleert de betaling van deze rentes boven de betaling van een schuld van lagere rang, zoals een legaat (art. 4:7 lid 1 onder h BW). Vermindering van een legaat op grond van artikel 4:120 lid $1 \mathrm{BW}$ of verhaal jegens een legataris ingevolge artikel 4:220 lid 3 BW is immers niet van toepassing als de voldoening van rentes pas aan de orde is na voldoening van de legaten.

De tweede zin van rechtsoverweging 2.21 maakt het er helaas niet duidelijker op. Daarin wordt overwogen dat de rentevorderingen op de uitdelingslijst kunnen worden opgenomen na de als boedelkosten aan te merken vereffeningskosten, waaronder het loon van vereffenaar. Los van het feit dat de Hoge Raad hiermee en passant een in de praktijk al aanvaarde, ${ }^{22}$ maar volgens mij nog niet eerder door de Hoge Raad bevestigde leer bekrachtigt, geeft dit geen antwoord op de vraag hoe dan precies met de rentes moet worden omgegaan. De zin 'pas na de als boedelkosten aan te merken vereffeningskosten' kan zien op de prioriteit die de voldoening van de boedelkosten dient te krijgen en als zodanig niets zeggen over de verdere rang, maar evengoed dat deze aansluitend als schuld als bedoeld in artikel 4:7 lid 1 onder a BW zijn aan te merken en daarmee van hoogste rang zijn. Daarbij moet er wel van worden uitgegaan dat de rente voortvloeit uit een verbintenis die als een schuld als bedoeld in artikel 4:7 lid 1 onder a BW is aan te merken.

\section{De duiding van de beantwoording van de prejudiciële vragen}

Rechtsoverwegingen 2.17 en 2.21 in samenhang met de beantwoording van de eerste prejudiciële vraag bezien, meen ik dat de Hoge Raad met de beantwoording van de derde vraag het volgende bedoelt.

Renteverplichtingen die voortvloeien uit een bij leven van de erflater bestaande of daaruit voortvloeiende verbintenis tussen de erflater en een schuldeiser zijn óók aan te merken als een schuld als bedoeld in artikel 4:7 lid 1 onder a BW. De vraag of een renteverplichting pas ontstaat op het moment dat deze opeisbaar wordt, ${ }^{23}$ of dat het een al bestaande periodieke verplichting tot betaling is, ${ }^{24}$ is in zoverre dan niet van belang.

In een situatie waarin de erfgenamen vereffenaar zijn, en er geen verzwaring van de vereffeningsverplichting op grond van artikel 4:218 BW heeft plaatsgevonden, en er sprake is van een positieve boedel, is duidelijk dat de (na overlijden doorlopende) rente dient te worden vol-

Richtlijnen Vereffening nalatenschappen (versie juli 2021, p. 23-24). Vgl. Biemans, Overeenkomst, overlijden en vereffening van nalatenschappen, Tijdschrift voor Insolventierecht 2020/41.

Vgl. Asser/Van Mierlo \& Krzeminski 3-VI 2020/49. 
daan uit het nalatenschapsvermogen of uit het vermogen van de erfgenaam op wie een van de in artikel 4:184 lid 2 BW genoemde gevallen van toepassing is. Indien een vereffenaar door de rechtbank is benoemd en deze niet verplicht is tot deponering van de uitdelingslijst vanwege artikel 4:221 lid $2 \mathrm{BW}$, omdat er sprake is van een positieve boedel, dient deze de (na overlijden doorlopende) rente te voldoen uit het beschikbare nalatenschapsvermogen.

Bij negatieve nalatenschappen ligt de beantwoording gecompliceerder. Indien de erfgenamen vereffenaar zijn, geldt niet zonder meer de verplichting tot deponering van een uitdelingslijst ex artikel 4:221 lid 1 BW. Dat laat onverlet dat een schuldeiser, die niet ten volle kan worden voldaan, vanzelfsprekend niet zonder meer genoegen hoeft te nemen met de enkele mededeling dat hij niet kan worden betaald. De erfgenaam zal dat aan de schuldeiser moeten melden (art. 4:214 lid 4 BW). De erfgenaam-vereffenaar is verplicht tot het deponeren van een boedelbeschrijving (art. 4:211 lid 3 BW) en moet de negatieve nalatenschap aan de kantonrechter melden (art. 4:199 lid 2 BW). De kantonrechter kan de erfgenaam-vereffenaar in het belang van de schuldeisers gebieden tot deponering van een uitdelingslijst over te gaan. De schuldeiser staan voldoende middelen ten dienste om de omvang van de boedel te kunnen verifiëren.

Voor de wijze waarop vervolgens moet worden omgegaan met de renteverplichting, kan het geen verschil maken of de erfgenaam de (negatieve) nalatenschap vereffent of dat een door de rechtbank benoemde vereffenaar dat doet en gehouden is tot het deponeren van een uitdelingslijst. Dat volgt ook uit rechtsoverweging 2.18:

'Met het oog op de rechtszekerheid is het wenselijk dat er voor rentevorderingen geen verschil in behandeling is tussen de verschillende wijzen van vereffening als hiervoor in 2.5 bedoeld.'

In rechtsoverweging 2.11 overweegt de Hoge Raad dat niet blijkt dat de wetgever de rechten van schuldeisers op een ander moment heeft willen fixeren dan op het tijdstip van het opmaken van de uitdelingslijst. Dat impliceert dat de hoogte van de rentevorderingen op de uitdelingslijst wordt vermeld per de datum van deponering. Dat is echter gezien de expliciete uitsluiting van het fixatiebeginsel van artikel $128 \mathrm{Fw}$ evenwel een in juridische zin niet te volgen uitgangspunt, omdat het toch een fixatie inhoudt. Waarom zou de schuldeiser wel recht hebben op rentebetaling uit de boedel vóór de deponering en niet meer vanaf dat moment? Het is niet ondenkbaar dat er tussen het moment van deponering en het daadwerkelijke moment van betaling nog geruime tijd ligt, met name wanneer een verzetprocedure wordt gevoerd.

Gezien de expliciete uitsluiting van het fixatiebeginsel door de Hoge Raad lijkt het passender om de rentever- plichtingen door te berekenen tot het moment van daadwerkelijke uitkering, dus na verbindendverklaring van de uitdelingslijst. Het is daarbij niet ongewoon om bepaalde pro-memorieposten op een uitdelingslijst op te nemen; zo wordt in de rechtspraak ${ }^{25}$ aanvaard dat ook het loon van een vereffenaar dat ná de deponering van de uitdelingslijst verschuldigd wordt op de gedeponeerde uitdelingslijst als pro-memoriepost wordt opgenomen en bij de (uiteindelijke) uitdelingslijst definitief wordt vastgesteld.

\section{Kritiek en onbeantwoorde vragen}

Uit de hiervoor en door de kantonrechter ${ }^{26}$ aangehaalde literatuur komt het beeld naar voren dat deze benadering door diverse auteurs niet als de meest redelijke zal worden aanvaard. Immers, de beschikbare en onder de schuldeisers te verdelen taart komt, naarmate de tijd verstrijkt, steeds meer toe aan de schuldeiser die een rente heeft bedongen en steeds minder aan schuldeisers voor wie dat niet het geval is. Lager gerangschikte schuldeisers zoals legatarissen en legitimarissen zouden, enkel door een rentebijtelling, zelfs wel eens achter het net kunnen vissen. ${ }^{27}$ Erfgenamen moeten mogelijk aan de zijlijn toekijken hoe de boedel verdampt doordat een steeds groter deel aan een schuldeiser met een rentedragende vordering moet worden afgedragen.

Het risico bestaat dat schuldeisers met een rentedragende vordering voordelen zien in het zo lang mogelijk uitstellen van de (ontvangst van de) betaling. Hoewel zij niet de regie voeren over de vereffening van de boedel, kunnen zij deze wel frustreren door bijvoorbeeld in voorkomende gevallen een beroep te doen op artikel 6:44 lid 3 BW, een procedure ex artikel 4:223 lid 2 BW te starten, het ontslag van een vereffenaar te vragen, in verzet te gaan tegen de uitdelingslijst, et cetera. Er dient dan ook voor te worden gewaakt dat hiervan misbruik wordt gemaakt. Sancties als het buiten toepassing laten van de rentebijtelling op grond van artikel 6:2 BW zijn in dat geval een optie.

De doorlopende renteverplichtingen zetten mogelijk meer druk op vereffenaars. Waar de ene partij profiteert, zal de andere mogelijk sneller vinden dat haar verkrijging uit de nalatenschap door een in haar ogen onvoldoende voortvarende behandeling door de vereffenaar te laag uitvalt.

Bijv. Rb. Gelderland 17 oktober 2014, ECLI:NL:RBGEL:2014:6626 en Rb. Amsterdam 3 augustus 2017, ECLI:NL:RBAMS:2017:5865. Zie ook S.R. Baetens, De uitdelingslijst en de verzetprocedure tijdens de wettelijke vereffening van een nalatenschap, Tijdschrift Relatierecht en Praktijk 2018, afl. 5, p. 383.

26 Rb. Noord-Holland 11 januari 2021, ECLI:NL:RBNHO:2021:205.

27 Biemans, Overeenkomst, overlijden en vereffening van nalatenschappen, Tijdschrift voor Insolventierecht 2020/41. 
Deze nadelen zijn mijns inziens echter niet onoverkomelijk en een inherent gevolg van het buiten toepassing laten van het faillissementsrechtelijke fixatiebeginsel van artikel $128 \mathrm{FW}^{28}$ Er valt bijvoorbeeld te denken aan het (al dan niet met instemming van de kantonrechter via de weg van art. 4:210 BW) uitbetalen van een voorschot op een (onbetwist) gedeelte van de verschuldigde hoofdsom, opdat de rentebijtelling verminderd wordt.

De beantwoording van de prejudiciële vragen laat nog enige relevante punten open. De Hoge Raad gaat niet in op de positie van separatisten. Dat lijkt ook niet nodig, omdat uit de wet (art. 4:223 lid 1 BW jo. art. 57-60 Fw) reeds volgt onder welke voorwaarden zij aanspraak kunnen maken op de betaling van rente.

In rechtsoverweging 2.17 wordt overwogen dat de renteverplichtingen zijn aan te merken als schulden als bedoeld in artikel 4:7 lid 1 onder a BW. Betekent dit ook dat de hoogte van de legitimaire massa hierdoor wordt beïnvloed? Artikel 4:65 BW bepaalt immers dat deze wordt bepaald met inachtneming van de schulden als bedoeld in artikel 4:7 lid 1 onder a BW. Per welke datum dient de legitimaire massa dan te worden vastgesteld? Dezelfde vragen kunnen worden gesteld voor legaten, waarvan de hoogte mede afhankelijk is van (bijvoorbeeld) de omvang van de nalatenschap.

De Hoge Raad concentreert zich op renteverplichtingen die voortvloeien uit een bij leven bestaande verbintenis. Deze vormen daarmee al een schuld als bedoeld in artikel 4:7 lid 1 onder a BW. Hoe het zit met andersoortige renteverplichtingen wordt niet bevestigd. Hierbij valt bijvoorbeeld met name te denken aan de verschuldigdheid van wettelijke rente. Indien er al sprake was van een verschuldigdheid vóór aanvang van de vereffeningsverplichting, lijkt het voorgaande mutatis mutandis te gelden. Maar kan er bijvoorbeeld wettelijke rente verschuldigd worden tijdens de vereffening? Kan bijvoorbeeld een legitimaris zijn legitieme portie bij een vereffenaar opeisen en aanspraak maken op wettelijke rente als niet tijdig wordt betaald? Weerhoudt artikel 4:223 lid 2 BW de vereffenaar in beginsel niet van voldoening van een schuld, waardoor nakoming feitelijk nog niet mogelijk is? Kan de vereffenaar dan wel in verzuim zijn? Dergelijke vragen laat de Hoge Raad onbeantwoord.

\section{Conclusie}

Dat de Hoge Raad duidelijk heeft aangegeven dat het faillissementsrechtelijke fixatiebeginsel van artikel 128 Fw niet van overeenkomstige toepassing is tijdens de wettelijke vereffening, draagt bij aan de rechtszekerheid. Helaas is niet eenduidig te stellen hoe deze renteverplichtingen bij (voornamelijk) negatieve nalatenschappen moeten worden betrokken, welke rang deze kennen en waar deze op een (eventuele) uitdelingslijst moeten worden vermeld. Verdedigbaar is dat de uitsluiting van het fixatiebeginsel ertoe leidt dat renteverplichtingen van dezelfde rang zijn als de vordering waar ze betrekking op hebben, en doorlopen tot de voldoening van de betreffende schuld of de uitbetaling conform de verbindend verklaarde uitdelingslijst.

De uitspraak van de Hoge Raad laat nog onduidelijkheden open over bepaalde gerelateerde vraagstukken, zoals de vraag of rente invloed heeft op de hoogte van de legitimaire massa. Of deze uitspraak ook geldt voor andersoortige renteverplichtingen als wettelijke rente, is evenmin volkomen duidelijk. 